\title{
Processing of Extrafoveal Objects During Multiple-Object Naming
}

\author{
Jane L. Morgan \\ Sheffield Hallam University
}

\author{
Antje S. Meyer \\ University of Birmingham
}

\begin{abstract}
In 3 experiments, the authors investigated the extent to which objects that are about to be named are processed prior to fixation. Participants named pairs or triplets of objects. One of the objects, initially seen extrafoveally (the interloper), was replaced by a different object (the target) during the saccade toward it. The interloper-target pairs were identical or unrelated objects or visually and conceptually unrelated objects with homophonous names (e.g., animal-baseball bat). The mean latencies and gaze durations for the targets were shorter in the identity and homophone conditions than in the unrelated condition. This was true when participants viewed a fixation mark until the interloper appeared and when they fixated on another object and prepared to name it while viewing the interloper. These results imply that objects that are about to be named may undergo far-reaching processing, including access to their names, prior to fixation.
\end{abstract}

Keywords: eye movements, object naming, homophones

Eye tracking has been an important tool for reading research for several decades (e.g., Liversedge \& Findlay, 2000; Rayner, 1998) and has been successfully applied in studies of auditory language processing (e.g., Altmann \& Kamide, 1999; Tanenhaus, SpiveyKnowlton, Eberhard, \& Sedivy, 1995). It has recently also gained some popularity in studies of language production (for reviews, see Griffin, 2004; Meyer \& Lethaus, 2004). In the production studies, speakers name or describe sets of objects or events, and eye tracking is used to examine when and for how long the speakers inspect each part of the display. This paradigm is particularly rich in promise for studies of phrase and sentence generation. To date, much of the experimental research into speech production has relied on measurements of speech onset latencies (e.g., Bock, 1996). Such latency-based paradigms are well suited to study the generation of single words but provide only limited evidence about the generation of longer utterances because these are often not fully planned before speech onset (e.g., F. Ferreira \& Swets, 2002; Meyer, 1996; Smith \& Wheeldon, 1999). As a consequence, the duration of planning processes that occur during speech are not reflected in the speech onset latencies. By contrast, a speaker's eye movements can be recorded before and after speech onset. If it can be shown that the eye movements speakers carry out when they speak about a scene or an event are systematically related to their speech planning processes, eye tracking can be used to study those planning processes that precede the onset of an utterance as well as those that are carried out during the articulation of an utterance.

Jane L. Morgan, School of Social Sciences and Law, Sheffield Hallam University, Sheffield, United Kingdom; Antje S. Meyer, School of Psychology, University of Birmingham, Birmingham, United Kingdom.

This research was supported by Economic and Social Research Council Grant R000239391, awarded to Antje S. Meyer. We thank Glyn Humphreys and Femke van der Meulen for their help and valuable discussions throughout the project.

Correspondence concerning this article should be addressed to Antje S. Meyer, School of Psychology, University of Birmingham, Edgbaston, Birmingham B15 2TT, United Kingdom. E-mail: a.s.meyer@bham.ac.uk
There is evidence from a number of studies that speakers' eye movements are indeed closely related to their speech planning processes. In a pioneering study, Griffin and Bock (2000) compared the eye movements of speakers describing line drawings of events in utterances such as "The mailman is chasing the dog" to the eye movements of viewers engaged in control tasks (preparing for later description, event comprehension, and mere viewing). On the basis of the similarities and differences found in the gaze patterns of the four groups, Griffin and Bock decomposed the cognitive processes preceding the generation of a descriptive utterance broadly into an apprehension phase, sufficient to understand the gist of the event, and a subsequent linguistic formulation phase, during which each event participant is inspected, just before being mentioned, for a little less than $1 \mathrm{~s}$ (see also Bock, Irwin, Davidson, \& Levelt, 2003; Griffin, 2004; Meyer \& Dobel, 2003).

Other eye tracking work has examined the coordination of eye gaze and speech during the description of simpler displays, usually sets of two to four objects, which are to be named in a specific order. We call this paradigm, which we used in the present study, the multiple-object naming paradigm. Studies using this paradigm have yielded a number of key findings. First, speakers rarely name objects without looking at them first. This is not too surprising given that objects can be seen most clearly when they are fixated on. Second, speakers usually inspect the objects in exactly the same order as they mention them. When speakers first mention an object and, later in the utterance, a property of the object, as in "The cat next to the chair is brown," they usually look at the object twice: once just before the onset of the noun and once just before the onset of the adjective (Meyer, van der Meulen, \& Brooks, 2004). This supports the conclusion by Griffin and Bock (2000) and Bock et al. (2003) that the eye gaze pattern during picture description is determined not exclusively by properties of the visual display but also by properties of the planned utterance.

Third, when speakers name several objects, their eyes usually move to a new object shortly before they initiate the name of the preceding object. Current evidence suggests that the gaze duration for an object (defined as the time interval between the onset of the 
first fixation and the end of the last successive fixation on the object) depends on the time required for identifying the object and for planning its name to the level of phonological form. Models of object naming differ in many ways, but they all agree that naming an object requires the speaker to carry out a sequence of planning steps: The object must be recognized, a suitable name must be selected from the mental lexicon, the morphological and phonological form of the name must be retrieved, and the corresponding articulatory commands must be generated (e.g., Caramazza, 1997; Dell, 1986; Humphreys \& Forde, 2001; Johnson, Paivio, \& Clark, 1996; Levelt, Roelofs, \& Meyer, 1999; for reviews see Levelt, 1999; Rapp \& Goldrick, 2000). In reaction time studies a number of variables have been identified that selectively affect the duration of specific planning steps, such as object recognition or the selection of the object's name from the mental lexicon. Eye tracking studies have shown that these same variables affect the time speakers spend looking at the objects they are about to name. For instance, Meyer, Sleiderink, and Levelt (1998) varied the ease of object recognition by presenting objects as normal line drawings or with partially deleted contours and found that both the naming latencies and the gaze durations were longer when the objects were shown in the contour-deleted version than in the normal version. Similarly, a variable that affects the ease of selecting an object name from the mental lexicon is name agreement (the likelihood that a group of speakers use the same name to refer to an object). This variable also been shown to affect both object naming latencies and gaze durations (Griffin, 2001). Furthermore, Belke, Meyer, and Damian (in press) showed that objects were named more slowly and inspected for longer when they were presented in semantically homogeneous blocks (e.g., cat, fish, duck, snake) than in unrelated blocks (e.g., cat, bus, chair, hat). These semanticblocking effects, like the effects of name agreement, can be allocated at the level of lexical selection. Finally, variables that affect the time required for retrieving the phonological forms of object names-for example, name frequency, name length, and phonological priming - have also been found to affect both object naming latencies and gaze durations (Griffin, 2001; Meyer, Roelofs, \& Levelt, 2003; Meyer et al., 1998; Meyer \& van der Meulen, 2000; but see Griffin, 2003). It seems, therefore, that the speaker's gaze remains on an object that is to be named until the object has been identified and the name has been planned to the level of phonological form. Only then do the eyes move on to the next object.

These results are of theoretical interest because they inform one about the coordination of visual information uptake and motor output during speech and can be compared to the coordination of information uptake and motor output in other tasks, for example, music reading (Gilman \& Underwood, 2003; Truitt, Clifton, Pollatsek, \& Rayner, 1997) or oral reading of text (e.g., Radach, Heller, \& Inhoff, 2003). They are also of methodological interest for speech production research, because they confirm that there are systematic links between eye gaze and speech planning: Speakers fixate on the objects they see in the order in which they plan their names, and the gaze duration for an object increases with the time required to identify the object and to plan its name. Thus, gaze durations can be used to estimate the time speakers require for processing objects during a naming task. It should be noted, however, that gaze durations are best viewed as measures of the relative difficulty of processing objects: The longer the gaze duration for an object, the longer the time a speaker requires for object identification and name retrieval. Gaze durations are not indicators of absolute processing time, simply because, as outlined earlier, the speaker's eyes usually move from object $n$ to object $n$ +1 before the name of object $n$ is initiated. Thus, there are late response preparation processes that are not captured in gaze durations (see also Meyer et al., 2003).

The present research is concerned with the processing of objects before fixation. We set out to examine whether the name of an object that is about to be mentioned is retrieved only when the object is fixated on or whether name retrieval can begin earlier, while another object is being fixated. This issue is important for a number of reasons. One reason is methodological: If name activation were to begin only after fixation onset, it would follow that the names of objects that have not been fixated have not been activated and that the moment of fixation onset could be taken to be the earliest moment at which lexical activation could begin. This would be useful information for researchers using eye tracking to study the scope of linguistic planning, that is, investigating issues such as whether speakers select all the words of a phrase before phrase onset or whether they need to identify the event or action and select the verb before beginning a sentence (e.g., F. Ferreira, 2000).

Determining whether object names become activated prior to fixation is also important for theoretical reasons. Theories of speech production must specify the temporal coordination of the conceptual and linguistic planning processes for successive parts of an utterance. Evidence about the relative timing of lexical retrieval processes for successive words of an utterance can, therefore, have important implications for models of speech planning, for instance, for assumptions about the selection of lexical units among competitors or about the serial ordering of activated units (e.g., Dell, Burger, \& Svec, 1997; Levelt \& Meyer, 2000; Vousden, Brown, \& Harley, 2000).

If the name of an object becomes activated only after the object is fixated on, the serial inspection of objects can be taken to be indicative of strictly serial lexical processing: A speaker fixates upon object $n$ until the phonological form of its name has been retrieved, then initiates the shift of gaze to object $n+1$, and subsequently retrieves its name. The interpretation of the alternative outcome-that is, evidence for lexical activation before the onset of fixation-is more complex. It could mean that the foveated object and the next object to be named are processed in parallel. Thus, speakers might preferentially process the foveated object, but concurrently the processing of the next object might begin, leading to the activation of the concept and the corresponding lexical information (see, e.g., Cave \& Bichot, 1999, for a discussion of models of attention compatible with such a proposal). Alternatively, the two objects might be processed in sequence, but activation of the name of object $n+1$ might begin before fixation. Studies of visual attention have shown that, under normal circumstances, that is, when viewers are not specifically instructed to dissociate their visual attention and eye gaze, shifts of eye gaze are preceded by corresponding shifts in the focus of visual attention (for further discussion of the relationship between eye gaze and visual attention, see, e.g., Deubel \& Schneider, 1996; Henderson, Pollatsek, \& Rayner, 1989; Hoffman \& Subramaniam, 1995; Irwin, 2004; Irwin \& Gordon, 1998). Therefore, there will be a time interval during which the speaker's focus of attention is directed at object $n+1$ but object $n$ is still being fixated. Speakers 
might attend to object $n$ until they have retrieved the phonological form of its name and then shift the focus of attention and simultaneously initiate the shift of gaze to object $n+1$. The retrieval of the name of object $n+1$ could begin after the shift of attention to that object but before the eye movement toward it has been completed (see Henderson \& Ferreira, 1990, 1993; Kennedy, 2000; Reichle, Pollatsek, Fisher, \& Rayner, 1998; Reichle, Rayner, \& Pollatsek, 2003, for discussions of related hypotheses concerning the allocation of attention to foveated and parafoveal words during reading).

To summarize, the activation of an object name could either begin after fixation onset, after the shift of attention to the object, or even earlier, while the focus of attention is still on the preceding object. The present experiments were not designed to discriminate between the latter two hypotheses but simply aimed to determine whether an object name could become activated before the object is fixated on. As explained above, determining when name activation begins is important for methodological as well as theoretical reasons.

The processing of information beyond the fovea has been investigated in other research contexts. One of them is reading research, which has shown that during the fixation of a word the next word can begin to be processed minimally to the level of abstract letter and phonological code retrieval for the initial part of the word. By contrast, the evidence for semantic analysis of parafoveal words is still controversial (e.g., Liversedge \& Findlay, 2000; Rayner, White, Kambe, Miller, \& Liversedge, 2003). The multiple-object naming task resembles reading in that a set of stimuli is processed in a particular order. As a consequence, the eye movements carried out by speakers and readers are similar in that most of the stimuli to be processed are looked at in a highly predictable order, and inspection times depend on the ease of processing of the stimuli. However, the tasks of reading and object naming differ in many ways too, for example, in the type of input (words vs. pictures) and the associated lexical retrieval processes (e.g., Job \& Tenconi, 2002; Lupker, Kinoshita, Coltheart, \& Taylor, 2003), the requirement to coordinate the visual information uptake with overt speech output and, linked to these differences, the speed with which the tasks are carried out. Thus, it is difficult to derive predictions about the processing of extrafoveal objects in the multiple-object naming tasks on the basis of the reading literature.

More directly relevant to our purposes are studies concerning the temporal and spatial integration of visual information across saccades. Much of this research has used versions of the boundary technique, which was introduced by Rayner (1975; McConkie \& Rayner, 1975) to study transsaccadic integration of information during reading. In a seminal study, Pollatsek, Rayner, and Collins (1984) asked participants to fixate on a mark until an object appeared in extrafoveal vision. The participants then carried out an eye movement to the location of the object. During the saccade, the original object (hereafter called the interloper) was replaced by a target object, which the participant had to name. In a series of experiments, the relationship between the interloper and the target was varied: They were identical, mirror images of each other, different in size, instances of the same concept (e.g., different line drawings of a cat), visually but not semantically related (e.g., a carrot and a baseball bat), semantically related (e.g., horse and cow), or they were visually and conceptually unrelated but had the same name (e.g., [baseball] bat and [animal] bat). Relative to a control condition in which an empty square was presented, Pollatsek et al. (1984) found shorter naming latencies in the identity condition, thus demonstrating that the interloper was processed and that this facilitated target naming. The other types of interlopers, with the exception of the semantically related ones, also consistently facilitated target naming, although the effects were weaker than that of identical interlopers. For our purposes, the preview benefit from homophonous interlopers is particularly important. Because target and interloper shared only the name, but were visually and conceptually unrelated, this effect constitutes compelling evidence that the name of the interloper object, which was never fixated on but appeared in the location of the target picture, was activated. Pollatsek et al. (1984) concluded that their results supported a model "in which only two kinds of information from the peripheral stimulus are used in naming the foveal stimulus: its visual features and its name" (p. 440).

Subsequent studies have provided additional evidence that viewers acquire and maintain fairly abstract representations of objects across saccades. For instance, Henderson and Siefert (1999; see also Henderson \& Siefert, 2001) used a paradigm very similar to that used by Pollatsek et al. (1984) to compare the preview benefits gained from identical interloper objects and mirror images of the targets relative to control conditions featuring unrelated objects or meaningless arrays. Corroborating the findings obtained by Pollatsek et al. (1984), they obtained preview benefits in both experimental conditions as well as a difference between the identical condition and the mirror-image condition. Furthermore, Pollatsek, Rayner, and Henderson (1990) found preview benefits when the interloper and target were identical objects but differed in size and when they appeared in different spatial positions. Henderson and Siefert (1999) proposed that viewers could generate abstract structural descriptions of extrafoveally viewed objects and match these onto stored object models. If a sufficient match is obtained, long-term memory information associated with the object model, such as the object's basic level category and its name, may be activated (for further discussion of the representations supporting transsaccadic integration, see also Carlson-Radvansky, 1999; Carlson-Radvansky \& Irwin, 1995; Germeys, de Graef, \& Verfaillie, 2002; Gordon \& Irwin, 2000; Henderson, 1994; Henderson \& Anes, 1994; Irwin, 1996; Kahneman, Treisman, \& Gibbs, 1992; Kanwisher \& Driver, 1992).

In sum, several studies have shown that extrafoveal objects can be processed to a conceptual level, which could support the activation of their names. To our knowledge, Pollatsek et al.'s (1984) study is the only one demonstrating that such early name activation indeed occurs. On the basis of these findings, one might expect that during a multiple-object naming task, the name of the next object to be named could become activated while the current object is being viewed. However, in the classic boundary experiments reviewed above, the interloper was processed while the participants were viewing a fixation stimulus and preparing an eye movement toward the interloper. In contrast, during multipleobject naming, the next object to be named is viewed while the speaker is preparing to name the current object. A number of studies have shown that less information is obtained from an extrafoveal stimulus when the processing load for the foveal stimulus is high than when it is lower (e.g., Henderson \& Ferreira, 1990; Ikeda \& Takeuchi, 1975; Kennedy, 1998; Liversedge \& 
Findlay, 2000). Because at least some of the processes involved in object naming require processing capacity (e.g., V. S. Ferreira \& Pashler, 2002), it is not certain that an extrafoveal object will be processed as thoroughly during multiple-object naming as suggested, for instance, by Pollatsek et al.'s (1984) results. On the other hand, in the classic boundary experiments the preview stimulus was displayed only during the time required for the viewer to initiate a saccade toward it (usually for less than $300 \mathrm{~ms}$ ), whereas in the multiple-object naming paradigm all objects are visible from trial onset, and the preview period (i.e., the presentation time prior to fixation) for the second object of a sequence is usually more than $600 \mathrm{~ms}$. Given the longer exposure time, viewers might be able extract more information from the preview stimulus than in the short exposure time used in the standard boundary paradigm.

The goal of Experiment 1 was to replicate the preview benefits from identical and homophonous interlopers reported by Pollatsek et al. (1984) using a slightly different procedure and new materials. The paradigm used in Experiments 2 and 3 combined features of the multiple-object naming task and the boundary paradigm. At trial onset, the participants saw three objects arranged in a triangle, which they were required to name in the following order: top left object, top right object, bottom object. The top right object was one of the interlopers used in Experiment 1. During the saccade from the top left to the top right quadrant of the screen, the interloper was replaced by a target object. As in Experiment 1, the interloper and target could be identical objects, objects with homophonous names, or unrelated objects. As an indicator of the time required for target processing we used the gaze duration for the target object. The goal of these experiments was to determine whether preview benefits from identical and homophonous interlopers would be obtained when participants fixated on another object and prepared to name it while viewing the interloper.

\section{Experiment 1}

The paradigm we used in the first experiment was similar to that used by Pollatsek et al. (1984) in their Experiment 6. At trial onset, the participants fixated on a cross on the left side of the screen until an object, the interloper, appeared on the right side. They were then required to look over to that location and name the object they saw. During the saccade, the interloper was replaced by a target object, which was either identical to the interloper, an unrelated object, or a conceptually unrelated object with the same name as the interloper (i.e., a homophone). The comparison of the effects of unrelated and identical interlopers allowed us to determine whether any processing of the interloper had occurred. The comparison of the effects of unrelated and homophonous interlopers allowed us to determine whether the name of the interloper was activated.

Our paradigm also differed from that used by Pollatsek et al. (1984) in a number of ways. One important difference was that together with the interloper an additional object was presented at the bottom of the screen; this object did not change, and participants named it after they named the target shown in the top right area of the screen. We included the additional object to be able to measure the gaze duration for the target object in addition to the naming latency and to determine whether similar patterns of results would be obtained for both dependent variables. This was important because in the following experiments we planned to rely exclusively on the target gaze duration as an estimate of the processing time for the target.

Pollatsek et al.'s (1984) experiment included a condition in which the interloper and target were mirror images of each other and a neutral condition in which an empty square was presented instead of the interloper. For our purposes, the mirror-image condition was not informative and was therefore not included. We replaced the neutral condition with a condition featuring an unrelated object because it seemed most appropriate to compare the effect of interloper objects with the same name as the target to the effect of comparable objects with a different name (see Henderson $\&$ Siefert, 1999, for a discussion of the relative merits of unrelatedobject and neutral baselines in this paradigm).

\section{Method}

Participants. All experiments were carried out with undergraduate students of the University of Birmingham. They were native speakers of English and had normal or corrected-to-normal vision. They received payment or course credits in return for their time. Each person took part in only one of the experiments. There were 19 participants in Experiment 1.

Materials and design. On each trial, the participants saw a fixation mark in the center of the top left quadrant of the screen; an interloper object, which was replaced by a target object, in the center of the top right quadrant; and another object displayed centrally in the bottom half of the screen. The fixation mark was a cross measuring approximately $1 \mathrm{~cm} \times 1$ $\mathrm{cm}$ (covering approximately $0.95^{\circ}$ ). The objects were shown as black line drawings on a light gray background. They fitted into frames of $6 \mathrm{~cm} \times 6$ $\mathrm{cm}\left(5.7^{\circ}\right)$. The distance between the center of the fixation mark and the center of the top left object was approximately $15 \mathrm{~cm}\left(14.0^{\circ}\right)$. The distance from the center of the fixation mark to the center of the bottom object, and from the center of the right object to the center of the bottom object, was also $15 \mathrm{~cm}$.

Forty-two line drawings were selected from a picture gallery provided by the Max Planck Institute for Psycholinguistics (Nijmegen, The Netherlands) or created by Jane L. Morgan (see Appendix). These pictures consisted of 14 interloper-target pairs with homophonous names and 14 unrelated objects to be shown in the bottom position of the displays. Fifty-six further drawings were selected from the same source to appear in the practice phase of the experiment only. These items were 28 pairs of drawings representing different tokens of the same basic category (e.g., two lamps).

Both members of each homophone pair were used as targets and as interlopers. Thus, the 14 homophonous interloper-target pairs yielded 28 different targets. Each target was tested in three conditions: (a) the identity condition, where the same object was used as interloper and target; (b) the homophone condition, where the target was preceded by a picture with the same name; and (c) the unrelated condition, in which the target was preceded by an unrelated object. The unrelated objects were the interlopers selected for other items. For instance, the target (animal) bat was combined with the unrelated interloper (spectacles) glasses. Thus, each of the 28 experimental items appeared three times as a target and once each as an identical, homophonous, and unrelated interloper. The homophonous targets were combined with the same object in the bottom position in all conditions. For example, the targets animal bat and baseball bat were both combined with the bottom object key. This ensured that the context in which the target name was produced was identical for each member of the homophone pair.

Each participant saw every target in all three experimental conditions. Three test blocks of 28 experimental trials were created. In each test block, every target appeared once and either 9 or 10 items were tested in each of the three experimental conditions. In each block, each target was preceded by a different type of interloper. The first test block began with eight 
practice trials in which objects drawn from the set of fillers were presented. On four practice trials the interlopers and targets were identical; on the remaining trials they were unrelated objects. Each of the six possible orders of the three blocks was used twice in the group of 12 participants whose data were included in the statistical analyses.

Given that the goal of the experiment was to investigate the effect of the match or mismatch of the target and interloper names, it was important that the members of each pair of homophones and of each unrelated pair were visually and semantically unrelated. We did not formally assess the degree of semantic similarity between targets and interlopers, but we did determine the degree of visual similarity. A paper-and-pencil rating study was carried out in which 20 participants rated object pairs using a 5-point scale to indicate the degree of visual similarity. Each participant rated the 14 homophone pairs and 14 of the 28 unrelated interloper-target pairs used in Experiment 1. In addition, all participants rated 14 pairs of identical objects, 14 pairs of objects from the same semantic category that looked similar, and 14 items that belonged to different semantic categories but looked similar (e.g., a banjo and a squash racket). As expected, high similarity ratings were given to identical pairs $(M=4.99)$, and intermediate ratings were given to the two types of visually similar items $(M \mathrm{~s}=$ 3.54 for members of the same category and 3.13 for members of different categories). The means for the homophonous and the unrelated interlopertarget pairs were much lower and quite similar $(M \mathrm{~s}=1.37$ for homophones and 1.13 for unrelated pairs); however, $t$ tests revealed that the difference between the homophonous and unrelated pairs was significant, $t_{l}(19)=$ $4.90, S E=.05, p<.01$, using participants as random variable, and $t_{2}(27)=2.39, S E=.1, p<.025$, using items as random variable. We discuss the implications of this finding below.

Apparatus. The experimental software package, Nijmegen Experimental Setup (provided by the Max Planck Institute for Psycholinguistics, Nijmegen, The Netherlands), was used to generate the experiment. The stimuli were presented on a 19-in. $(48.3-\mathrm{cm})$ Samtron 95P Plus color monitor (resolution $=42.1 \mathrm{dpi}$, refresh rate $=85 \mathrm{~Hz}$ ). Each participant's speech was recorded using a Sony microphone and a Sony digital audiotape recorder. Speech onset latencies were measured using a voice key (Hasomed GmbH, Magdeburg, Germany). Eye movements were recorded using an SMI EyeLink two-dimensional head-mounted eye tracking system, which estimated the positions of both eyes every $4 \mathrm{~ms}$.

Procedure. To establish whether the name of the interloper was activated, it was crucial that the participants used the expected object names. To ensure that this would be the case on most trials, before the main experiment we conducted a training session in which the participants named all objects appearing on experimental trials twice in isolation and naming errors were corrected. They also named the 56 filler items mentioned above. These items were included in an effort to divert the participants' attention from the fact that the materials included a substantial number of objects with homophonous names.

In the training session, each picture was displayed as a black line drawing in the center of the computer screen for 3,000 ms. Participants were instructed to produce the first name that came to mind. Items were presented twice over two blocks. If a participant named an object incorrectly in the first block, he or she was shown the picture in a printed picture booklet, told the correct name, and asked to use this name when the picture was displayed a second time.

After the training session, the headband of the eye tracker was placed on the participant's head, and the system was calibrated. The practice trials and experimental trials then followed. At the beginning of each trial, a fixation mark was presented on the left side of the computer screen for 500 $\mathrm{ms}$, after which the interloper and bottom object were simultaneously displayed. Standardized instructions required the participants to fixate on the cross until the objects were presented, after which they should look at the right object, name it, and then look at and name the bottom object.

During the saccade from the fixation mark to the right object, the interloper was replaced by a target object. The display change was initiated as soon as a right-eye saccade crossing the vertical midline of the screen was detected and took maximally $16 \mathrm{~ms}$ to complete. The eye movement from the midline to the landing position on the right side took, on average, $23 \mathrm{~ms}$. Therefore, the target was usually in place when the eyes landed on the right side of the screen (but see the Experiment 1 Results section). The target and the bottom object remained in view until 4,500 ms after trial onset. A fixed intertrial interval of $2,500 \mathrm{~ms}$ was used. The participants were asked to name the targets using bare nouns. In the instructions no mention was made of the display changes. During the debriefing session following the experiment, some of the participants spontaneously reported having noticed the picture change. An experimental session lasted approximately $45 \mathrm{~min}$.

Analysis of eye movements. The EyeLink software determines the average position and duration of eye fixations between saccades. We used the Cognitive Parsing algorithm of the software package, which defines saccades as eye movements covering a minimum of $0.15^{\circ}$ of visual angle at a minimum velocity of $30 \%$ with an acceleration of minimally $8000 \% \mathrm{~s}^{2}$. The movements of both eyes were recorded, but only the data for the right eye were analyzed. The spatial accuracy of the eye tracking system is about $0.1^{\circ}$ of visual angle. We defined fixations as being on the fixation mark when their distance to the center of the mark was less than $3^{\circ}$. We categorized fixations as being on one of the objects when they fell within a virtual frame of $6 \mathrm{~cm} \times 6 \mathrm{~cm}\left(5.7^{\circ} \times 5.7^{\circ}\right)$ enclosing the object. The participants were instructed to look at the fixation mark at the beginning of each trial. We sometimes observed that the first fixation of a trial was located slightly below or to the left or right of the fixation mark. This typically was seen on a number of successive trials. We corrected for such drifts by manually aligning the first fixation with the fixation mark. The positions of the remaining fixations of the trial were recomputed accordingly. If the first fixation did not fall within approximately $6^{\circ}$ of the fixation mark, the trial was discarded. Gaze durations rather than individual fixation durations were analyzed. We calculated the gaze duration for a region of interest by subtracting the onset time of the first fixation on the region from the offset time of the last fixation in a set of consecutive fixations before the shift of gaze to a location outside the region of interest. Thus, gaze duration, as defined here, includes the durations of any intraobject saccades.

\section{Results}

In all experiments, we excluded and replaced any participants who lost more than $33 \%$ of their data points. In Experiment 1, we had to exclude 7 of 19 participants. Three participants were excluded because of technical problems involving the eye tracker or the voicekey. Two participants were excluded because on more than one third of the trials they failed to carry out an eye movement to the right side of the screen. Hence, the display change was not initiated and the participants named the interloper instead of the target. Finally, a further 2 participants were excluded because on more than one third of the trials they carried out an eye movement triggering the display change, but their eyes did not land in target region.

The data from the remaining 12 participants were included in the analyses. Individual trials were removed when participants did not name the target correctly (five cases, including three cases when the name of the interloper was produced), when they did not name the bottom object correctly (two cases), when the speech onset latency exceeded 2,000 ms (nine cases), and when the voicekey was not triggered by the participant's speech (nine cases). In addition, $11 \%$ of the trials (114 trials) were excluded because participants failed to look at the stimuli in the expected order (top left object, top right object, bottom object). This left a 
data set containing observations from 869 trials. As noted above, the display change from interloper to target was initiated as soon as a saccade crossing the vertical midline of the screen was detected and could take up to $16 \mathrm{~ms}$ to complete. On $88 \%$ of these 869 trials (768 trials), the time interval between the moment when the display change was initiated and the onset of the first fixation on the right side of the midline was longer than $16 \mathrm{~ms}$; thus, on these trials the display change was completed by the time the participants fixated on the target location. However, on $12 \%$ of the trials (101 trials) a fixation onset was registered less than $16 \mathrm{~ms}$ after the display change had been initiated. On these trials, the participants may have briefly fixated on the interloper before it was replaced by the target. We eliminated all trials (43 trials, $4.2 \%$ of the trials) on which the fixation time on the interloper could have exceeded $3 \mathrm{~ms}$.

The overall rates of missing data points per condition are shown in Table 1. Analyses of variance (ANOVAs) of the rates of missing values after arcsin transformation (see Winer, Brown, \& Michels, 1991 ) showed that there was no significant difference between the three conditions; $F_{1}(2,22)=3.12, M S E=0.03$, using participants as a random variable, and $F_{2}(2,54)=1.87, M S E=0.14$, using items as a random variable.

The participants were instructed to look at the fixation mark on the left side of the screen until the interloper object appeared. The mean latency to initiate the saccade toward the interloper was 236 ms. As shown in Table 1, the saccade latencies were very similar across the experimental conditions, and ANOVAs showed that they did not differ significantly from each other, $F_{1}(2,22)<1$, $F_{2}(2,54)=1.14, M S E=1,965$.

The dependent variables of primary interest were the naming latency, measured from target onset, and the gaze duration for the target object. The mean naming latency was shortest in the identity condition and longest in the unrelated condition (see Table 1). ANOVAs yielded a significant main effect of condition, $F_{1}(2$, $22)=35.46, M S E=3,326, p<.01$, and $F_{2}(2,54)=43.48$, $M S E=6,700, p<.01$. Subsequent $t$ tests demonstrated that the 193 -ms difference between the identity and unrelated conditions was highly significant, $t_{1}(11)=9.74, S E=20, p<.01$, and $t_{2}(27)=9.30, S E=22, p<.01$. The 54-ms difference between the homophone condition and the unrelated condition reached significance according to the analysis by items, $t_{2}(27)=3.12$, $S E=22, p<.01$, but just missed significance according to the analysis by participants, $t_{1}(11)=2.53, S E=21, p=.028$.

Table 1

Results of Experiment 1: Mean Saccade Latencies, Gaze Durations for Targets, Target-Naming Latencies (in Milliseconds), and Percentages of Missing Values Per Condition

\begin{tabular}{|c|c|c|c|c|c|c|c|}
\hline \multirow[b]{2}{*}{ Condition } & \multicolumn{2}{|c|}{$\begin{array}{l}\text { Saccade } \\
\text { latency }\end{array}$} & \multicolumn{2}{|c|}{$\begin{array}{l}\text { Target } \\
\text { gaze } \\
\text { duration }\end{array}$} & \multicolumn{2}{|c|}{$\begin{array}{l}\text { Target } \\
\text { naming } \\
\text { latency }\end{array}$} & \multirow{2}{*}{$\begin{array}{c}\text { Missing } \\
\text { values } \\
(\%)\end{array}$} \\
\hline & $M$ & $S E$ & $M$ & $S E$ & $M$ & $S E$ & \\
\hline Identity & 234 & 28 & 520 & 45 & 708 & 28 & 17 \\
\hline Homophone & 243 & 31 & 612 & 50 & 847 & 46 & 22 \\
\hline Unrelated & 232 & 31 & 679 & 55 & 901 & 36 & 16 \\
\hline
\end{tabular}

Because we carried out two $t$ tests involving the unrelated condition, we used an adjusted significance level of $p<.025$.

As mentioned above, we calculated the gaze duration for an object by subtracting the onset time of the first fixation on a target from the offset time of the last fixation on the target before the shift of gaze to the bottom object. On most trials, the participant's gaze either remained on the bottom object until the end of the trial or returned to the fixation mark, presumably in preparation for the next trial. On occasion, participants looked at the target, then at the bottom object, and then again at the target. The second gaze to the target usually occurred at the very end of the trial, while the name of the bottom object was being produced. It was clearly not related to the processes involved in identifying the target or selecting its name. Therefore, we only included the first-pass gaze durations in the analyses.

As the data in Table 1 show, the same pattern of results was obtained for the gaze durations as for the naming latencies. The mean gaze duration was shortest in the identity condition, intermediate in the homophone condition, and longest in the unrelated condition. The main effect of condition was significant, $F_{1}(2$, $22)=39.22, M S E=1,966, p<.01$, and $F_{2}(2,54)=37.19$, $M S E=5,287, p<.01$. The $t$ tests we conducted showed that the 159-ms difference between the identity and the unrelated conditions was significant, $t_{1}(11)=8.05, S E=20, p<.01$, and $t_{2}(27)=7.45, S E=22, p<.01$, as was the $67-\mathrm{ms}$ difference between the homophone and the unrelated condition, $t_{1}(11)=$ 4.12, $S E=16, p<.01$, and $t_{2}(27)=5.32, S E=14, p<.01$.

The visual similarity rating in the pretest was slightly, but significantly, higher for the homophonous than for the unrelated pairs $(M \mathrm{~s}=1.37$ vs. 1.13$)$. To examine the contribution of visual similarity to the preview benefits observed in the homophone condition, we computed for each of the 28 items the difference in the similarity scores given to the homophonous pair (e.g., baseball bat-animal bat) and to the corresponding unrelated pair (glassesanimal bat) and correlated this difference with the size of the preview benefit from homophonous relative to unrelated interlopers obtained for the speech onset latencies and for the gaze durations. Neither of the correlations $(r=.15$ and $r=.05, d f=27)$ approached significance. There were two items that received mean similarity ratings above 2 on the 5-point scale. When these items were eliminated from the analyses we found the same pattern of results as for the complete data set: In the analyses of the speech onset latencies, the preview benefit from homophonous interlopers reached significance in the analyses by items only, $t_{1}(11)=1.51$, $S E=26$, and $t_{2}(23)=2.47, S E=23, p<.025$. In the analyses of the target gaze durations, the preview benefit was significant in both analyses, $t_{1}(11)=2.75, S E=21, p<.025$, and $t_{2}(23)=$ 4.38, $S E=15, p<.01$. These results strongly suggest that visual similarity did not contribute substantially to the preview effects. ${ }^{1}$

\footnotetext{
${ }^{1}$ We carried out the same analyses for Experiments 2 and 3. The correlations between the difference in the similarity ratings for homogeneous and unrelated pairs and the preview benefit in the homophone relative to the unrelated condition for the gaze durations were low ( $r=.12$ and $r=15, d f=27$, for Experiments 2 and 3, respectively) and not significant. Furthermore, in both experiments the preview benefit remained significant when the two homophone pairs with the highest similarity scores in the pretest and the corresponding unrelated pairs were excluded from the analyses.
} 


\section{Discussion}

For the target naming latencies, we replicated the pattern of results reported by Pollatsek et al. (1984). Relative to the baseline condition (which was different in the two studies), there was a substantial preview benefit (i.e., a reduction in the naming latencies) in the identity condition. There was a smaller preview benefit in the homophone condition, which was significant in the analysis by items but just failed to reach the .025 level of significance we adopted in the analysis by participants.

The results obtained for the mean gaze durations, which were not recorded in Pollatsek et al.'s (1984) study, were similar: The gaze durations were shortest in the identical condition, intermediate in the homophone condition, and longest in the unrelated condition. For the gaze durations, the difference between the homophone and unrelated conditions was significant according to the analysis by participants and by items. These differences between the experimental conditions demonstrate that the participants processed the interlopers, which in turn affected the processing of the targets. The identical interlopers may have facilitated the visual-conceptual processing of the targets as well as the retrieval of their names. By contrast, the homophonous interlopers were not visually or conceptually similar to the targets but only had the same name. Therefore, the preview benefit from homophonous interlopers demonstrates that the names of the interlopers were accessed.

\section{Experiment 2}

In Experiment 1, the participants viewed the interloper while looking at the fixation mark and preparing a saccade toward the interloper. The question we addressed in Experiment 2 was whether the name of an extrafoveally viewed interloper would also be activated when the participants were fixating and preparing to name another object while the interloper was shown. There is evidence that extrafoveal stimuli are processed less efficiently when the processing load for the foveal stimulus is high compared to when it is low (e.g., Henderson \& Ferreira, 1990; Kennedy, 1998). Therefore, it was not certain that the preview benefits found in Experiment 1 would be replicated when the fixation cross was replaced by an object that was to be named.

In Experiment 2, sets of three objects, arranged in a triangular formation, were shown from trial onset. The participants were asked to named the objects in the following order: top left object, top right object, bottom object. As before, the object shown in the top right position was the critical one. During the saccade toward that position, the object shown at trial onset (the interloper) was replaced by a new object (the target). As in Experiment 1, the interloper and target were either unrelated, had homophonous names, or were identical. Note, however, that the interloper was now visible from trial onset rather than only during the period when the participants planned a saccade toward it.

In this experiment, the first object to be named was the object in the top left position. The target was the second object to be named. Earlier studies have shown that speakers producing several object names in succession often do not fully plan all of them before speech onset (e.g., Meyer, 1996; Smith \& Wheeldon, 1999; see also F. Ferreira \& Swets, 2002). Therefore, the speech onset latencies were unlikely to show any effects of interloper process- ing on target processing. To assess the time required to process the target and to retrieve its name, we measured the gaze duration for the targets, which was shown to be sensitive to the effects of the different types of interlopers in Experiment 1.

We were concerned that the participants might be aware of the interloper-target changes and that this might yield viewing patterns for the pictures that would be different from those observed during standard multiple-object naming experiments. For instance, participants might look to the right object earlier than they would normally do in order to remove the interloper and see the target instead. Alternatively, they might fixate on the left object for a longer period than they would do for a stable display in order to be able to identify the interloper. To assess whether the participants' eye gaze pattern differed from the pattern observed for stable displays, we included a baseline condition in which an independent group of participants simply named the left object, the target, and the bottom object. No display changes occurred in this group of participants. We compared the results obtained from this group of participants with the results obtained in the identity condition of the group experiencing the display changes.

\section{Method}

Participants. Experiment 2 was carried out with 29 participants. The data of 24 participants (12 from each of two groups) were analyzed.

Materials. The same materials were used as in Experiment 1. In addition, 14 new line drawings with monosyllabic names were selected to appear in the top left position of the screen, replacing the fixation mark of Experiment 1 (see Appendix for a listing of the objects). These objects were not related conceptually or in the phonological form of their names to the objects with which they were combined, and they were chosen from the pool of fillers presented in the practice session. They were shown in the same size as the top right object, that is, fitting into frames of $6 \mathrm{~cm} \times 6 \mathrm{~cm}$. The midpoint-to-midpoint distance between the frames for the top left and top right objects was $15 \mathrm{~cm}\left(14.0^{\circ}\right)$. Both members of the homophonous pairs were displayed with the same top left and bottom object in all three conditions; for instance, the targets animal bat and baseball bat were both combined with the top left object pie and the bottom object key.

Design. Two groups of participants (Groups A and B) were tested. The design used in Group A was the same as in Experiment 1. Thus, each of the 28 target objects was presented three times: (a) once preceded by a homophonous interloper, (b) once by an unrelated interloper, and (c) once by an interloper that was identical to the target. The experimental trials were preceded by eight practice trials. The only difference from Experiment 1 was that the fixation mark was replaced with a line drawing of an object.

In Group B, the same combinations of top left, target, and bottom objects were shown as in Group A, but there were no interlopers; instead, the participants saw the target pictures from trial onset.

Procedure. The experiment began with a training session in which the participants named all line drawings that were to be shown in the experiment and the filler items. As in Experiment 1, each picture was shown for $3,000 \mathrm{~ms}$, and naming errors were corrected. Then the headband of the eye tracker was positioned, and the participants received standardized instructions that detailed where on the screen the three objects would be presented and the order in which they should be named. Participants were instructed to name the objects using bare nouns only. No mention was made of the display changes occurring in Group A.

The trial structure used for testing Group A was as follows: Each trial began with the presentation of a fixation mark in the center of the top left quadrant of the screen. After $800 \mathrm{~ms}$, the top left object, the interloper, and the bottom object were shown. During the saccade from the top left to the 
top right region of the screen, the interloper was replaced by the target object. The three objects were removed 4,000 $\mathrm{ms}$ after picture onset.

In Group B, the fixation mark was shown for $800 \mathrm{~ms}$, followed by the simultaneous presentation of the top left object, targets, and bottom object, which remained in view for $4,000 \mathrm{~ms}$. In both groups, fixed intertrialintervals of $2,500 \mathrm{~ms}$ were used.

\section{Results}

We first report the results from participants experiencing the display changes (Group A) and then compare these findings with those obtained for the group naming stable displays (Group B).

Group A (display changes). Five of 17 participants were excluded and replaced. Two participants failed to carry out an eye movement toward the interloper on more than one third of the trials and consequently did not see the target but only the interloper on those trials. Two participants failed to inspect the objects in the expected order (left object, target object, bottom object) on more than one third of the trials. Finally, the data from 1 participant were discarded because the gaze duration for the target was almost twice the mean gaze duration observed for the remaining participants.

The results obtained from the remaining 12 participants of Group A are summarized in Table 2. Twenty-nine trials (2.9\% of the data) were excluded because participants used incorrect names for the left object or they hesitated (2 cases), because they did not name the target correctly (19 cases, 14 of which were trials on which the name of the interloper was used), or misnamed the bottom object ( 7 cases) or all three objects (1 case). Forty-one trials $(4.1 \%$ of the data) were excluded because the response latency exceeded $2,000 \mathrm{~ms}$, and 8 trials $(0.8 \%$ of the data) were excluded because the voicekey was not triggered by the participant's speech.

Other trials were lost because participants did not inspect the objects in the expected order (50 trials, $5 \%$ of the trials) or because the display change was not completed before or within $3 \mathrm{~ms}$ after the onset of the first fixation on the right side of the screen (35 trials, $3.5 \%$ of the trials).

ANOVAs showed that the percentages of missing observations differed significantly between the three conditions, $F_{1}(2,22)=$ 8.48, MSE $=0.04, p<.01$, and $F_{2}(2,54)=6.40, M S E=0.09$, $p<.01$. Pairwise comparisons showed that only the difference between the unrelated condition and the identity condition was significant, $t_{1}(11)=3.46, S E=0.09, p<.01$, and $t_{2}(27)=3.48$, $S E=0.08, p<.01$.
Table 2 also displays the mean speech onset latencies and the mean gaze durations for the left object, which were very similar for the three conditions. This was to be expected because the display change occurred only after the shift of gaze from the left to the right object had been initiated.

For the target gaze durations, we obtained a similar pattern as in Experiment 1, with the mean gaze duration being substantially shorter in the identity and the homophone conditions than in the unrelated condition. The main effect of interloper type was significant, $F_{1}(2,22)=24.29, M S E=3,960, p<.01$, and $F_{2}(2,54)=$ 45.88, MSE $=4,768, p<.01$. We conducted $t$ tests that showed that the unrelated condition differed significantly from the identity condition, $t_{1}(11)=5.01, S E=35, p<.01$, and $t_{2}(27)=8.95$, $S E=19, p<.01$, and from the homophone condition, $t_{1}(11)=$ 6.60, $S E=19, p<.01$, and $t_{2}(27)=5.59, S E=22, p<.01$.

Comparison with Group B (no display changes). The percentage of discarded trials in Group B was $8 \%$. There were 18 naming errors: 3 concerning the left object and 13 concerning the target object. On 2 trials, all three objects were named incorrectly. On 60 trials ( $6 \%$ of the trials), participants did not look at the objects in the expected order.

The mean speech onset latency was 902 ms, which was slightly longer than the mean observed in the identity condition of Group A $(882 \mathrm{~ms})$, but this difference was not significant, $t_{1}(22)<1$, and $t_{2}(27)=1.64, S E=14$. The gaze duration for the left object was $657 \mathrm{~ms}$, which is very close to the corresponding gaze duration for the identity condition of Group A (661 ms). Unexpectedly, the target gaze duration was shorter in Group B $(500 \mathrm{~ms})$ than in the identity condition of Group A (575 ms). This difference was statistically significant according to the analysis by items, $t_{2}(27)=$ $6.40, S E=12, p<.01$, but not according to the analysis by participants, $t_{1}(22)=1.32, S E=58$.

\section{Discussion}

In this experiment, the preview benefits from identical and homophonous interlopers found in our Experiment 1 and in Pollatsek et al.'s (1984) Experiment 6 were replicated. As we explained in the beginning of this article, one might have expected these effects to be weakened or to disappear when the task of inspecting a fixation mark and looking at the interloper location as soon as the interloper appeared was replaced by the more demanding multiple-object naming task. Contrary to this expectation, the

Table 2

Results of Experiment 2: Mean Gaze Durations for the Left Object and Target (in Milliseconds), Mean Speech Onset Latencies (in Milliseconds), and Percentages of Missing Values per Group and Condition

\begin{tabular}{|c|c|c|c|c|c|c|c|}
\hline \multirow[b]{2}{*}{ Condition } & \multicolumn{2}{|c|}{$\begin{array}{l}\text { Gaze duration } \\
\text { for left object }\end{array}$} & \multicolumn{2}{|c|}{$\begin{array}{l}\text { Gaze duration } \\
\text { for target }\end{array}$} & \multicolumn{2}{|c|}{$\begin{array}{l}\text { Speech onset } \\
\text { latency }\end{array}$} & \multirow{2}{*}{$\begin{array}{c}\text { Missing } \\
\text { values } \\
(\%)\end{array}$} \\
\hline & $M$ & $S E$ & $M$ & $S E$ & $M$ & $S E$ & \\
\hline \multicolumn{8}{|c|}{ Group A (display changes) } \\
\hline Identity & 661 & 36 & 575 & 18 & 882 & 34 & 13 \\
\hline Homophone & 662 & 34 & 627 & 21 & 869 & 36 & 17 \\
\hline Unrelated & 657 & 35 & 749 & 30 & 879 & 26 & 22 \\
\hline \multicolumn{8}{|c|}{ Group B (no display changes) } \\
\hline Identity & 657 & 69 & 500 & 54 & 902 & 45 & 8 \\
\hline
\end{tabular}


preview benefit from homophonous interlopers was numerically larger in Experiment 2 (122 ms) than in Experiment 1 (67 ms). The interaction between experiment and interloper type was significant in the analysis by participants but only approached significance according to the analysis by items, $F_{I}(1,22)=4.87, M S E=$ $1,851, p<.05$, and $F_{2}(1,27)=3.19, M S E=4,605, p=.09$. This difference in the size of the effects might be related to the fact that the interloper was available to be viewed for much longer in Experiment 2 (on average for $660 \mathrm{~ms}$ ) than in Experiment 1 (on average for $236 \mathrm{~ms}$ ). The preview benefit from the identical interloper was roughly the same in both experiments $(159 \mathrm{~ms}$ and $174 \mathrm{~ms}$ ), possibly because this effect had reached its maximal strength in Experiment 1.

The mean gaze durations for the left object were virtually identical in the group of participants who experienced display changes and the group who named stable displays. This is important because it demonstrates that the display changes did not encourage participants to fixate on the left object for a longer or shorter time than they would do when naming stable objects. Thus, the exposure time for the interlopers corresponded well to the time that speakers naming stable displays viewed the right object extrafoveally while preparing to name the left object. Had we found a substantial difference in gaze durations for the left objects, it would be difficult to generalize from the preview benefits observed here to benefits obtained from previewing stable targets during standard naming tasks. Furthermore, there is no evidence that the participants in the two groups differed in their processing of the right objects while they were looking at the left object. If, for instance, the participants experiencing display changes had allocated substantially more processing resources to the extrafoveal right object than the participants naming stable pictures, one might have expected to see longer gaze durations for the left object in the former than in the latter group.

The group experiencing display changes spent slightly, although not significantly, more time fixating on the targets than the group carrying out the standard naming task. Some participants of Group A spontaneously commented on the display changes during the debriefing session after the experiment. It is possible that they engaged in additional self-monitoring processes triggered by their awareness that the extrafoveally viewed object and the foveated target could differ. Alternatively, they might have postponed the shift of gaze to the bottom object on some of the trials to ensure that they would not miss a display change.

\section{Experiment 3}

The paradigm used in the present study can be viewed as a priming paradigm, with the interlopers priming target processing. A robust finding in the priming literature is that the size of priming effects often depends on the proportion of trials featuring related prime-target pairs, with higher proportions leading to stronger priming effects (e.g., Bodner \& Masson, 2004). This is true when participants can consciously identify the primes as well as when the primes are masked and therefore unlikely to be consciously identified. One account of this relatedness proportion effect in paradigms using identifiable primes links it to the participants' attempts to use the primes to predict the targets: When the proportion of related primes is high, the participants are more likely to attempt to predict the target on the basis of the prime than when the proportion is low (for further discussion see, e.g., Neely, 1991).

In Experiments 1 and 2, the interloper and target had the same name on two thirds of the trials. Because of the high proportion of related trials one might be concerned that the observed preview benefits were exclusively due the participants' strategic use of the interlopers. The comparison between the two groups of participants tested in Experiment 2, who did or did not experience display changes, suggests that the participants who viewed the interlopers did not attend more to the right object than the participants who did not experience display changes. This finding argues against the view that the participants in the display-change condition attempted to predict the targets on the basis of the interlopers. However, this is a null result and therefore needs to be interpreted with caution. We conducted Experiment 3 to examine further the importance of the strategic use of the interlopers. We eliminated the identical condition and replaced the corresponding trials with trials featuring unrelated interlopers. Consequently, the interloper and target had the same name on only one third of the trials, and only on those trials would interloper processing be beneficial to target processing. The question to be addressed was whether the preview benefit in the homophone condition would still be seen or whether it would disappear. The latter result would imply that the preview benefits observed earlier were largely or exclusively due to the participants' attempts to guess the upcoming target on the basis of the interloper.

\section{Method}

Participants. The experiment was carried out with 18 participants. The data from 12 participants were included in the analyses.

Materials and design. The same pictures were used as in Experiment 2. As already mentioned, in the unrelated condition the same interlopers were used as in the homophone condition, but they were coupled with different targets (e.g., the interloper glasses [spectacles] was combined with the target bat [animal]). To create the new filler items, we assigned each interloper to a second unrelated target. For instance, the interloper glasses was now also combined with the target horn (antler). The objects in the filler pairs were not related conceptually or in the form of their names.

As before, each target was shown three times. Each target was preceded once by the same unrelated interloper and once by the same homophonous interloper as in Experiments 1 and 2. However, the targets were no longer combined with identical interlopers but instead with the newly selected unrelated interlopers. These new unrelated trials were treated as fillers and were not included in the analyses.

Procedure. The procedure was the same as in Experiment 2.

\section{Results and Discussion}

Six participants were excluded and replaced. One participant failed to carry out an eye movement toward the interloper, and 2 participants did not look at the three objects in the expected order on more than one third of the trials. Three further participants were excluded because of technical problems involving either the eye tracker or the voicekey.

The results obtained from the remaining 12 participants are summarized in Table 3. For experimental trials, there were 19 naming errors in total ( $2.7 \%$ of the data): 5 on the left object, 12 on the target ( 7 of which were cases where the interloper was named), and 1 on the bottom object. On one trial the voicekey was 
Table 3

Results of Experiment 3: Mean Gaze Durations for the Left Object and Target (in Milliseconds), Mean Speech Onset

Latencies (in Milliseconds), and Percentages of Missing Values Per Condition

\begin{tabular}{lcccccccc}
\hline & $\begin{array}{c}\text { Gaze } \\
\text { duration } \\
\text { for left } \\
\text { object }\end{array}$ & & $\begin{array}{c}\text { Gaze } \\
\text { duration } \\
\text { for target }\end{array}$ & & \multicolumn{2}{c}{$\begin{array}{c}\text { Speech } \\
\text { onset } \\
\text { latency }\end{array}$} & \\
\cline { 2 - 3 } Condition & $M$ & $S E$ & $M$ & $S E$ & & $M$ & $S E$ & $\begin{array}{c}\text { Missing values } \\
(\%)\end{array}$ \\
\hline $\begin{array}{l}\text { Homophone } \\
\text { Unrelated }\end{array}$ & 642 & 50 & 589 & 36 & 794 & 45 & 11 \\
\hline
\end{tabular}

not triggered by the participant's speech. Fifty-five trials (5\% of the trials) were excluded from the analyses because the participants did not look at the objects in the expected order; 42 trials (4\%) were excluded because the display change was not completed before the onset of the first fixation on the right object or within 3 $\mathrm{ms}$ after fixation onset. The overall rates of missing observations were similar for the two experimental conditions (both $t \mathrm{~s}<1$ ).

The mean speech onset latency was shorter in the unrelated condition than in the homophone condition, but this difference was not significant, $t_{1}(11)=1.31, S E=21$, and $t_{2}(27)=1.63, S E=$ 19. A difference in speech onset latencies was not expected because the target was not the first object to be named. The mean gaze duration for the left object was slightly shorter in the unrelated condition than in the homophone condition, but this difference was not significant either (both $t \mathrm{~s}<1$ ). By contrast, the gaze duration for the target was shorter by $74 \mathrm{~ms}$ in the homophone condition than in the unrelated condition, and this difference was significant, $t_{1}(11)=4.44, S E=17, p<.01$, and $t_{2}(27)=4.00$, $S E=20, p<.01$.

This preview benefit was numerically smaller than the corresponding effect found in Experiment 2, which was $122 \mathrm{~ms}$. However, in a joint ANOVA on the results from both experiments, this difference in the effect sizes did not approach significance, $F_{1}(1$, $22)=3.86, M S E=1,865$, and $F_{2}(1,27)=2.25, M S E=5,612$, both $p \mathrm{~s}>.10$. Overall, the participants of Experiment 3 reacted somewhat faster than those of Experiment 2. This was reflected in the average speech onset latencies, the gaze durations for the left object, and the gaze durations for the right object. None of these differences between the experiments reached significance. Nevertheless, the small difference in the overall response speed of the participants in the two experiments may have contributed to the observed difference in the size of the priming effects. For the present purposes, the most important finding is that the preview benefit was replicated when the proportion of related interlopertarget pairs was low (one third). This demonstrates that the effect was not likely to be solely caused by the participants' attempts to predict the targets on the basis of the interlopers.

\section{General Discussion}

The goal of the experiments reported above was to determine whether the name of an object that is about to be named can become activated before the object is fixated on. In Experiment 1 we used a technique similar to that used by Pollatsek et al. (1984).
The participant viewed a fixation mark until an interloper object appeared to its right, which was replaced by a target object during the participant's saccade toward it. The participant first named the target and, deviating from the technique used by Pollatsek et al. (1984), then named a second object shown at the bottom of the screen. The mean naming latencies and gaze durations for the targets were shorter when the interloper and target were identical than when they were different objects. This demonstrates that the participants processed the interloper and that information gleaned from the interloper was maintained across the saccade and influenced the processing of the target. More important is that the naming latencies and gaze durations were also reduced when the interloper and target were different objects with the same name. For instance, seeing a baseball bat as an interloper facilitated the subsequent naming of the animal bat displayed in the same position. This preview benefit from homophonous interlopers constitutes evidence that the name of the interloper was activated, which is, of course, exactly the same conclusion Pollatsek et al. (1984) drew 20 years ago. Several studies have included some of the conditions tested by Pollatsek et al. 1984 (e.g., Henderson \& Siefert, 1999; Pollatsek et al., 1990), but to the best of our knowledge the present study is the first to replicate the preview benefit from homophonous interlopers.

Having replicated the basic pattern of results reported by Pollatsek et al. (1984) using a paradigm very similar to that in the original study, we altered the paradigm to investigate the processing of extrafoveal interlopers during a multiple-object naming task. In Experiments 2 and 3, the fixation mark on the left side of the screen was replaced by an object, which had to be named. The interloper, still shown on the right side of the screen, was presented from trial onset. During the eye movement from the first to the second object, the interloper was replaced by a target. As in Experiment 1, the mean gaze durations for the targets were shorter after identical and homophonous interlopers than after unrelated interlopers. Thus, the participants recognized the interloper and activated its name even when they were fixating another object and preparing to name it while the interloper was presented. The preview benefit from homophonous interlopers was maintained when the proportion of trials featuring related interloper-target pairs was reduced from two thirds (Experiment 2) to one third (Experiment 3). It is therefore unlikely that the preview benefit stemmed exclusively from the participants' attempts to predict the targets on the basis of the interlopers.

\section{Methodological Implications of the Results}

We found that the gaze durations for the targets systematically depended on the type of interloper. Identical interlopers may have facilitated the visual and conceptual processing of the targets as well as the retrieval of their names. The homophonous interlopers probably facilitated mainly the retrieval of the sound forms of the target names, although, as we discuss below, there may have been some facilitation of conceptual processing as well due to feedback from the sound form to superordinate levels of processing. Our results support the conclusion from earlier studies that the time speakers spend gazing at objects they are about to name depends on the time they require to identify the objects and to retrieve their names (for reviews, see Griffin, 2004; Meyer \& Lethaus, 2004). Therefore, gaze durations can be used to estimate the processing 
times for the objects speakers talk about: The more time it takes to formulate an utterance about an object, the longer speakers will look at the object. Most of the earlier studies have addressed the relationship between the gaze duration and the time required to plan an utterance about the first object in a sequence. The results of our Experiments 2 and 3, along with those reported by Griffin (2001), demonstrate that gaze durations systematically depend on the processing times for objects named utterance-internally as well. This is important because, as explained in the beginning of this article, the planning of utterance-internal words and phrases cannot be easily examined using speech onset latencies. By contrast, eye tracking can be used to study the planning processes for utterance-initial as well as utterance-internal words and phrases.

To the best of our knowledge, the present study is the first to combine a version of the classic boundary technique with a multiple-object naming task. As the display change occurred during a saccade, the change itself could not be seen. However, because of the size and placement of the interloper objects, the participants could easily identify them while fixating on the left object, and it is not surprising that many participants were aware of the fact that interloper and target could be different. However, there was no evidence that this greatly affected the way they processed the displays and planned the utterances about them. Thus, the methodology introduced here may be a useful tool for future language production research. One might, for instance, use it to study how extensively extrafoveal objects are processed when they are named as part of the same or different syntactic constituent or sentence as the foveated object, or to determine whether the extent to which the extrafoveal objects are processed depends on the speaker's speech rate or planning strategy.

The present results also highlight a limitation of the use of eye tracking in speech production research. One might wish to use eye tracking to determine when speakers begin to process different parts of a display and link this information to their speech output. For instance, Levelt and Meyer (2000) reviewed the eye tracking studies conducted by Meyer et al. (1998) and by Meyer and van der Meulen (2000), which showed that speakers fixated on each object to be named until they had retrieved its phonological form. They concluded that speakers shifted attention from one object to the next as late as possible, that is, just in time to be able to complete preparing the name of object $n+1$ before the end of the name of object $n$. They speculated that speakers might use such a highly sequential processing strategy to minimize their processing load. Implicit in Levelt and Meyer's argument was the assumption that the processing of an object begins only after fixation. Our findings indicate that this assumption is incorrect. Our present results suggest that a substantial part of the processing of an object that is about to be fixated and named may be done prior to fixation; therefore, the onset of fixation on an object does not necessarily correspond to the onset of object processing.

\section{Issues for Further Research}

Our claims concerning the activation of the names of extrafoveally viewed objects are based on experiments using a rather special set of object pairs, namely, pairs with homophonous names. We used homophonous interloper-target pairs because in these items the degree of name similarity is maximized. An obvious question for further research is whether preview benefits would also be obtained for other types of phonologically similar interloper-target pairs, such as mat-bat or back-bat.

There are different proposals in the speech production literature concerning the representation of homophones. One view is that homophones have separate conceptual and syntactic representations (lemmas) but shared morphological and phonological representations (Cutting \& Ferreira, 1999; Jescheniak \& Levelt, 1994; Jescheniak, Meyer, \& Levelt, 2003). An alternative view is that homophones have independent conceptual and lexical representations but are linked to the same set of phonological segments (e.g., Caramazza, Bi, Costa, \& Miozzo, 2004; Caramazza, Costa, Miozzo, \& Bi, 2001). Both views can account for the observed preview benefit from homophones. If homophones share a morpheme, the effect can be explained by assuming that a homophonous interloper activates the morpheme and phonological segments shared with the target. In addition, activation might spread from these representations to the target lemma and the target concept (e.g., Cutting \& Ferreira, 1999; V. S. Ferreira \& Griffin, 2003). This preactivation of lexical and possibly conceptual units facilitates target processing relative to the control condition in which the interloper activates an unrelated morpheme and an unrelated set of segments. If homophones have separate morphological representations, the preview benefit can be attributed entirely to the activation of the shared segments or to segmental activation and feedback from the segmental to the morpheme level and, possibly, superordinate levels.

Whether a preview benefit would be obtained from phonologically related, but not homophonous, interlopers should depend on the relative contribution of the activation of the morpheme and the segments and on the existence of feedback links between the phonological and the morphological level. Research into the effects of phonologically related interlopers should help to determine the origin of the preview effects-whether they are primarily phonologically or morphologically based. Given that robust priming effects from phonologically related primes have been obtained in other picture-naming paradigms (e.g., Costa \& Caramazza, 2002; Glaser \& Glaser, 1989; Jerger, Martin, \& Damian, 2002; Meyer \& Schriefers, 1991; Meyer \& van der Meulen, 2000; Morsella \& Miozzo, 2002), we would expect to see evidence for phonological priming from extrafoveally viewed interlopers to foveated targets as well.

A second issue raised by the current findings is when the preview benefit arose. We have already briefly discussed this point in the beginning of this article. One possibility is that the speakers initially focus exclusively on the left object, until the phonological form of its name has been retrieved, and then shift attention to the right object. The eye movement to the right object would be programmed approximately at the same time, resulting in a time period before the eyes land on the right object during which that object would already be the focus of attention. ${ }^{2}$ The processing of the interloper could begin during this period. Alternatively, speakers might initially fixate on the left object and prioritize its processing but simultaneously allocate some attention to the right

\footnotetext{
${ }^{2}$ Models of reading sometimes assume different criteria for the programming of a saccade and the shift of attention to a new stimulus (see, e.g., Reichle et al., 1998, 2003, for further discussion). At present, we see no need to stipulate this for multiple-object naming.
} 
object. Consequently, the interloper concept and the associated lexical information might become activated before the focus of attention shifts toward the interloper location. The first proposal endorses a classic moving-spotlight metaphor of the allocation of attention and assumes that at any moment in time only one object is attended to. The second proposal endorses the view that attention can be allocated to several objects in parallel (see, e.g., Cave $\&$ Bichot, 1999, for further discussion). Thus, the question of when the preview effect arose is closely linked to the question of how speakers allocate attention to several objects they have to name. The present data do not allow us to trace the time course of the development of the preview effects. As we explained earlier, our goal was to determine whether the name of the extrafoveally viewed interloper was activated to the extent that the processing of the target would be affected. This was shown to be the case.

A third issue is when the processing of the interloper ended. ${ }^{3}$ An obvious possibility is that the interloper was processed until it was replaced by the target. Accordingly, the interloper object was recognized; that is, the corresponding concept was activated, and activation was passed on to the lemma and the morphological and possibly phonological representation of the associated word form. When the interloper was replaced by the target, the interloper concept and the associated linguistic units received no further activation, and their activation levels quickly decayed. This view is in line with the assumption made in current models of speech production (e.g., Dell, Burger, \& Svec, 1997) that the activation of "past" units- that is, units that do not receive any further top-down input—rapidly decays. This assumption explains, for instance, that speakers are generally more likely to make anticipatory rather than perseveratory speech errors. However, it is possible that even after the interloper had been replaced by the target, high-level representations activated by the interloper continued to activate subordinate representations and that the activation levels of the morphological and phonological representations of the interloper continued to increase for a short time after the withdrawal of the interloper. Additional research is necessary to trace the exact time course of interloper activation. We would expect that any variable affecting the speed of identifying the extrafoveal object (e.g., familiarity with the object, presentation in a canonical or unusual orientation, distance to the foveated object) or the speed of retrieving its name (e.g., name agreement, frequency) should affect the likelihood of the name being activated prior to fixation on the object. The easier it is for the speaker to process the extrafoveal object, the more likely the name of the object should be to be activated before fixation onset.

A final question raised by our findings is whether activation of the object name is confined to the next object to be fixated and named or whether the names of other extrafoveally viewed objects, which may be named later or not at all, can also become activated. As we explained earlier, the name of an object will be activated only if the corresponding concept is sufficiently activated (e.g., Humphreys \& Forde, 2001). This, in turn, may presuppose that the object is attended to (for further discussion, see, e.g., Germeys et al., 2002; Henderson \& Hollingworth, 2003; Henderson \& Siefert, 1999, 2001; Rensink, 2000a, 2000b). Whether conceptual activation is sufficient for name activation, as some cascaded models of speech production assume (e.g., Caramazza, 1997; Humphreys, Riddoch, \& Quinlan, 1988; but see Bloem \& La Heij, 2003), or whether name activation only occurs when the viewer selects the concept and the corresponding lexical unit to be part of an utterance plan, as serial stage models assume (e.g., Levelt et al., 1999), remains to be seen (see Damian \& Bowers, 2003; Morsella \& Miozzo, 2002, for further discussion).

\section{Concluding Remarks}

Our experiments showed that speakers can begin to process an object that they are about to name well before the eyes land on the object and that the information acquired from the extrafoveal preview of the object is maintained across the saccade toward it and facilitates the processing of the object after fixation. Preview benefits were obtained from homophonous as well as identical interlopers, which demonstrates that not only conceptual but also word form information is accessed during the extrafoveal preview of the object.

Given these results, which show that objects are extensively processed prior to fixation, one may ask why speakers naming several objects usually fixate on each of them instead of relying entirely on the extrafoveal information (e.g., Meyer et al., 1998; Meyer et al., 2004). Further research is necessary to answer this question. We believe that the extensive processing of the extrafoveal objects is a consequence of the speaker's intention to fixate on the object and of the associated shift of attention toward it. Meyer and van der Meulen (2000) and Meyer and Lethaus (2004) have proposed that as a default strategy participants plan an eye movement to all objects they are required to name, perhaps primarily because fixating on the objects facilitates object recognition. The eye movement to a new object is preceded by a shift of attention that allows for the concept of the upcoming fixation target and the corresponding lexical units to become activated. Thus, it might not be the case that objects are fixated on although they have been thoroughly processed before fixation but that certain objects are thoroughly processed because eye movements are planned toward them.

\footnotetext{
${ }^{3}$ We thank Z. Griffin for bringing this point to our attention.
}

\section{References}

Altmann, G. T., \& Kamide, Y. (1999). Incremental interpretation at verbs: Restricting the domain of subsequent reference. Cognition, 73, 247-264.

Belke, E., Meyer, A. S., \& Damian, M. F. (in press). Refractoriness in the semantic system. Quarterly Journal of Experimental Psychology.

Bloem, I., \& La Heij, W. (2003). Semantic facilitation and semantic interference in word translation: Implications for models of lexical access in speech production. Journal of Memory and Language, 48, $468-488$.

Bock, K. (1996). Language production: Methods and methodologies. Psychonomic Bulletin \& Review, 3, 395-421.

Bock, K., Irwin, D. E., Davidson, D. J., \& Levelt, W. J. M. (2003). Minding the clock. Journal of Memory and Language, 48, 653-685.

Bodner, G. E., \& Masson, M. E. J. (2004). Beyond binary judgment: Prime validity modulates masked repetition priming in the naming task. Memory \& Cognition, 32, 1-11.

Caramazza, A. (1997). How many levels of processing are there in lexical access? Cognitive Neuropsychology, 14, 177-208.

Caramazza, A., Bi, Y., Costa, A., \& Miozzo, C. (2004). What determines the speed of lexical access: Homophone or specific-word frequency? A 
reply to Jeschniak et al. (2003). Journal of Experimental Psychology: Learning, Memory, and Cognition, 30, 278-282.

Caramazza, A., Costa, A., Miozzo, M., \& Bi, Y. (2001). The specific-word frequency effect: Implications for the representation of homophones in speech production. Journal of Experimental Psychology: Learning, Memory, and Cognition, 27, 1430-1451.

Carlson-Radvansky, L. A. (1999). Memory for relational information across eye movements. Perception \& Psychophysics, 61, 919-934.

Carlson-Radvansky, L. A., \& Irwin, D. E. (1995). Memory for structural information across eye movements. Journal of Experimental Psychology: Learning, Memory, and Cognition, 21, 1441-1458.

Cave, K. R., \& Bichot, N. P. (1999). Visuospatial attention beyond a spotlight model. Psychonomic Bulletin \& Review, 6, 204-223.

Costa, A., \& Caramazza, A. (2002). The production of noun phrases in English and Spanish: Implications for the scope of phonological encoding in speech production. Journal of Memory and Language, 46, $178-$ 198.

Cutting, J. C., \& Ferreira, V. S. (1999). Semantic and phonological information flow in the production lexicon. Journal of Experimental Psychology: Learning, Memory, and Cognition, 25, 318-339.

Damian, M. F., \& Bowers, J. S. (2003). Locus of semantic interference in picture-word interference tasks. Psychonomic Bulletin \& Review, 10, 111-117.

Dell, G. S. (1986). A spreading-activation theory of retrieval in sentence production. Psychological Review, 93, 283-321.

Dell, G. S., Burger, L. K., \& Svec, W. R. (1997). Language production and serial order: A functional analysis and a model. Psychological Review, 104, 123-147.

Deubel, H., \& Schneider, W. X. (1996). Saccade target selection and object recognition: Evidence for a common attentional mechanism. Vision Research, 36, 1827-1837.

Ferreira, F. (2000). Syntax in language production: An approach using tree-adjoining grammars. In L. R. Wheeldon (Ed.), Aspects of language production (pp. 291-330). East Sussex, England: Psychology Press.

Ferreira, F., \& Swets, B. (2002). How incremental is language production? Evidence from the production of utterances requiring the computation of arithmetic sums. Journal of Memory and Language, 46, 57-84.

Ferreira, V. S., \& Griffin, Z. M. (2003). Phonological influences on lexical (mis)selection. Psychological Science, 14, 86-90.

Ferreira, V. S., \& Pashler, H. (2002). Central bottleneck influences on the processing stages of word production. Journal of Experimental Psychology: Learning, Memory, and Cognition, 28, 1187-1199.

Germeys, F., de Graef, P., \& Verfaillie, K. (2002). Transsaccadic perception of saccade target and flanker objects. Journal of Experimental Psychology: Human Perception and Performance, 28, 868-883.

Gilman, E., \& Underwood, G. (2003). Restricting the field of view to investigate the perceptual spans of pianists. Visual Cognition, 10, 201232

Glaser, W. R., \& Glaser, M. O. (1989). Context effects in Stroop-like word and picture processing. Journal of Experimental Psychology: General, $118,13-42$.

Gordon, R. D., \& Irwin, D. E. (2000). The role of physical and conceptual properties in preserving object continuity. Journal of Experimental Psychology: Learning, Memory, and Cognition, 26, 136-150.

Griffin, Z. M. (2001). Gaze durations during speech reflect word selection and phonological encoding. Cognition, 82, B1-B14.

Griffin, Z. M. (2003). A reversed word length effect in coordinating the preparation and articulation of words in speaking. Psychonomic Bulletin \& Review, 10, 603-609.

Griffin, Z. M. (2004). Why look? Reasons for speech-related eye movements. In J. M. Henderson \& F. Ferreira (Eds.), The interface of language, vision, and action: What we can learn from free-viewing eye tracking (pp. 213-247). New York: Psychology Press.
Griffin, Z. M., \& Bock, K. (2000). What the eyes say about speaking. Psychological Science, 11, 274-279.

Henderson, J. M. (1994). Two representational systems in dynamic visual identification. Journal of Experimental Psychology: General, 123, 410426.

Henderson, J. M., \& Anes, M. D. (1994). Roles of object-file review and type priming in visual identification within and across eye fixations. Journal of Experimental Psychology: Human Perception and Performance, 20, 826-839.

Henderson, J. M., \& Ferreira, F. (1990). Effects of foveal processing difficulty on the perceptual span in reading: Implications for attention and eye movement control. Journal of Experimental Psychology: Learning, Memory, and Cognition, 16, 417-429.

Henderson, J. M., \& Ferreira, F. (1993). Eye movement control during reading: Fixation measures reflect foveal but not parafoveal processing difficulty. Canadian Journal of Experimental Psychology, 47, 201-221.

Henderson, J. M., \& Hollingworth, A. (2003). Eye movements and visual memory: Detecting changes to saccade targets in scenes. Perception \& Psychophysics, 65, 58-71.

Henderson, J. M., Pollatsek, A., \& Rayner, K. (1989). Covert visual attention and extrafoveal information use during object identification. Perception \& Psychophysics, 45, 196-208.

Henderson, J. M., \& Siefert, A. B. C. (1999). The influence of enantiomorphic transformation on transsaccadic object integration. Journal of Experimental Psychology: Human Perception and Performance, 25, 243 255.

Henderson, J. M., \& Siefert, A. B. C. (2001). Types and tokens in transsaccadic object identification: Effects of spatial position and leftright orientation. Psychonomic Bulletin \& Review, 8, 753-760.

Hoffman, J. E., \& Subramaniam, B. (1995). The role of visual attention in saccadic eye movements. Perception \& Psychophysics, 57, 787-795.

Humphreys, G. W., \& Forde, E. M. E. (2001). Hierarchies, similarity, and interactivity in object recognition: "Category-specific" neuropsychological deficits. Behavioural and Brain Sciences, 24, 453-509.

Humphreys, G. W., Riddoch, M. J., \& Quinlan, P. T. (1988). Cascade processes in picture identification. Cognitive Neuropsychology, 5, 67103.

Ikeda, M., \& Takeuchi, T. (1975). Influence of foveal load on the functional visual field. Perception \& Psychophysics, 18, 255-260.

Irwin, D. E. (1996). Integrating information across saccadic eye movements. Current Directions in Psychological Science, 5, 94-100.

Irwin, D. E. (2004). Fixation location and fixation duration as indices of cognitive processes. In J. M. Henderson \& F. Ferreira (Eds.), The interface of language, vision, and action: What we can learn from free-viewing eye tracking (pp. 105-133). New York: Psychology Press.

Irwin, D. E., \& Gordon, R. D. (1998). Eye movements, attention and trans-saccadic memory. Visual Cognition, 5, 127-155.

Jerger, S., Martin, R., C., \& Damian, M., F. (2002). Semantic and phonological influences on picture naming by children and teenagers. Journal of Memory and Language, 47, 229-249.

Jescheniak, J. D., \& Levelt, W. J. M. (1994). Word-frequency effects in speech production: Retrieval of syntactic information and of phonological form. Journal of Experimental Psychology: Learning, Memory, and Cognition, 20, 824-843.

Jescheniak, J. D., Meyer, A. S., \& Levelt, W. J. M. (2003). Specific-word frequency is not all that counts in speech production: Comments on Caramazza, Costa et al. and new experimental data. Journal of Experimental Psychology: Learning, Memory, and Cognition, 29, 432-438.

Job, R., \& Tenconi, E. (2002). Naming pictures at no costs: Asymmetries in picture and word conditional naming. Psychonomic Bulletin \& Review, 9, 790-794.

Johnson, C. J., Paivio, A., \& Clark, J. M. (1996). Cognitive components of picture naming. Psychological Bulletin, 120, 113-139.

Kahneman, D., Treisman, A., \& Gibbs, B. J. (1992). The reviewing of 
object files: Object-specific integration of information. Cognitive Psychology, 24, 175-219.

Kanwisher, N., \& Driver, J. (1992). Objects, attributes, and visual attention: Which, what, and where. Current Directions in Psychological Science, 1, 26-31.

Kennedy, A. (1998). The influence of parafoveal words on foveal inspection time: Evidence for a processing trade-off. In G. Underwood (Ed.), Eye guidance in reading and scene perception (pp. 149-223). Oxford, England: Elsevier.

Kennedy, A. (2000). Parafoveal processing in word recognition. Quarterly Journal of Experimental Psychology, 53A, 429-455.

Levelt, W. J. M. (1999). Models of word production. Trends in Cognitive Sciences, 3, 223-232.

Levelt, W. J. M., \& Meyer, A. S. (2000). Word for word: Multiple lexical access in speech production. European Journal of Cognitive Psychology, $12,433-452$

Levelt, W. J. M., Roelofs, A., \& Meyer, A. S. (1999). A theory of lexical access in language production. Behavioral and Brain Sciences, 22, 1-38.

Liversedge, S. P., \& Findlay, J. M. (2000). Saccadic eye movement and cognition. Trends in Cognitive Sciences, 4, 6-14.

Lupker, S. J., Kinoshita, S., Coltheart, M., \& Taylor, T. E. (2003). Mixing costs and mixing benefits in naming words, pictures, and sums. Journal of Memory and Language, 49, 556-575.

McConkie, G. W., \& Rayner, K. (1975). The span of effective stimulus processing during a fixation in reading. Journal of Experimental Psychology: Human Perception and Performance, 22, 563-581.

Meyer, A. S. (1996). Lexical access in phrase and sentence production: Results from picture-word interference experiments. Journal of Memory and Language, 35, 477-496.

Meyer, A. S., \& Dobel, C. (2003). Application of eye tracking in speech production research. In J. Hyönä, R. Radach, \& H. Deubel (Eds.), The mind's eye: Cognitive and applied aspects of eye movement research (pp. 253-272). Amsterdam: Elsevier Science.

Meyer, A. S., \& Lethaus, F. (2004). The use of eye tracking in studies of sentence generation. In J. M. Henderson \& F. Ferreira (Eds.), The interface of language, vision, and action: What we can learn from free-viewing eye tracking (pp. 191-211). New York: Psychology Press.

Meyer, A. S., Roelofs, A., \& Levelt, W. J. M. (2003). Word length effects in picture naming: The role of a response criterion. Journal of Memory and Language, 47, 131-147.

Meyer, A. S., \& Schriefers, H. (1991). Phonological facilitation in pictureword interference experiments: Effects of stimulus onset asynchrony and types of interfering stimuli. Journal of Experimental Psychology: Learning, Memory, and Cognition, 17, 1146-1160.

Meyer, A. S., Sleiderink, A. M., \& Levelt, W. J. M. (1998). Viewing and naming objects: Eye movements during noun phrase production. Cognition, 66, B25-B33.

Meyer, A. S., \& van der Meulen, F. F. (2000). Phonological priming of picture viewing and picture naming. Psychonomic Bulletin \& Review, 7, 314-319.

Meyer, A. S., van der Meulen, F. F., \& Brooks, A. (2004). Eye movements during speech planning: Speaking about present and remembered objects. Visual Cognition, 11, 553-576.
Morsella, E., \& Miozzo, M. (2002). Evidence for a cascade model of lexical access in speech production. Journal of Experimental Psychology: Learning, Memory, and Cognition, 28, 555-563.

Neely, J. H. (1991). Semantic priming effects in visual word recognition: A selective review of current findings and theories. In D. Besner \& G. W. Humphreys (Eds.), Basic processes in reading: Visual word recognition (pp. 264-336). Hillsdale, NJ: Erlbaum.

Pollatsek, A., Rayner, K., \& Collins, W. E. (1984). Integrating pictorial information across eye movements. Journal of Experimental Psychology: General, 113, 426-442.

Pollatsek, A., Rayner, K., \& Henderson, J. M. (1990). Role of spatial location in integration of pictorial information across saccades. Journal of Experimental Psychology: Human Perception and Performance, 16, 199-210.

Radach, R., Heller, D., \& Inhoff, A. W. (2003). A comparison of silent and oral reading. In Abstracts of the 44th Meeting of the Psychonomic Society, Abstract No. 4074, p. 94.

Rapp, B., \& Goldrick, M. (2000). Discreteness and interactivity in spoken word production. Psychological Review, 107, 460-499.

Rayner, K. (1975). The perceptual span and peripheral cues in reading. Cognitive Psychology, 7, 65-81.

Rayner, K. (1998). Eye movements in reading and information processing: 20 years of research. Psychological Bulletin, 124, 372-422.

Rayner, K., White, S. J., Kambe, G., Miller, B., \& Liversedge, S. P. (2003). On the processing of meaning from parafoveal vision during eye fixations in reading. In J. Hyönä, R. Radach, \& H. Deubel (Eds.), The mind's eye: Cognitive and applied aspects of eye movement research (pp. 213-234). Amsterdam: Elsevier.

Reichle, E. D., Pollatsek, A., Fisher, D. L., \& Rayner, K. (1998). Toward a model of eye movement control in reading. Psychological Review, 105, $125-157$.

Reichle, E. D., Rayner, K., \& Pollatsek, A. (2003). The E-Z-Reader model of eye-movement control in reading: Comparisons to other models. Behavioral and Brain Sciences, 26, 445-526.

Rensink, R. A. (2000a). The dynamic representation of scenes. Visual Cognition, 7, 17-42.

Rensink, R. A. (2000b). Seeing, sensing, and scrutinizing. Vision Research, 40, 1469-1487.

Smith, M., \& Wheeldon, L. R. (1999). High level processing scope in spoken sentence production. Cognition, 73, 205-246.

Tanenhaus, M. K., Spivey-Knowlton, M. J., Eberhard, K. M., \& Sedivy, J. C. (1995, June 16). Integration of visual and linguistic information in spoken language comprehension. Science, 268, 1632-1634.

Truitt, F. E., Clifton, C., Pollatsek, A., \& Rayner, K. (1997). The perceptual span and the eye-hand span in sight-reading music. Visual Cognition, 4, 143-161.

Vousden, J. I., Brown, G. D. A., \& Harley, T. A. (2000). Serial control of phonology in speech production: A hierarchical model. Cognitive Psychology, 41, 101-175.

Winer, B. J., Brown, D. R., \& Michels, K. M. (1991). Statistical principles in experimental design (3rd ed.). New York: McGraw-Hill. 
Appendix

Names of Objects Presented in Experiments 1-3

\begin{tabular}{|c|c|c|c|}
\hline \multicolumn{2}{|c|}{ Target objects } & \multirow{2}{*}{$\begin{array}{c}\text { Top left } \\
\text { object }\end{array}$} & \multirow{2}{*}{$\begin{array}{l}\begin{array}{c}\text { Bottom } \\
\text { object }\end{array} \\
\text { Cup }\end{array}$} \\
\hline Boy (child) & Buoy (life) & & \\
\hline Spade (tool) & Spade (card) & Lamp & Fire \\
\hline Bow (arrow) & Bow (ribbon) & Card & Fork \\
\hline Bat (animal) & Bat (baseball) & Pie & Key \\
\hline Pipe (drain) & Pipe (smoking) & Anchor & Horse \\
\hline Mouse (rodent) & Mouse (computer) & Tie & Drum \\
\hline Nail (finger) & Nail (hammer) & Candle & Leaf \\
\hline Tank (fish) & Tank (military) & Dog & Sock \\
\hline Chest (trunk) & Chest (body) & Egg & Scissors \\
\hline Table (furniture) & Table (chart) & Belt & Axe \\
\hline Nut (walnut) & Nut (bolt) & Cat & Baby \\
\hline Horn (hooter) & Horn (antler) & Pen & Apple \\
\hline Flour (bread) & Flower (plant) & Clown & Tent \\
\hline Glasses (spectacles) & Glasses (wine) & Car & Bird \\
\hline
\end{tabular}

Note. Glosses are given in parentheses in order to disambiguate the homophonous stimuli.

Received April 14, 2004

Revision received November 22, 2004

Accepted December 1, 2004

\section{E-Mail Notification of Your Latest Issue Online!}

Would you like to know when the next issue of your favorite APA journal will be available online? This service is now available to you. Sign up at http://watson.apa.org/ notify/ and you will be notified by e-mail when issues of interest to you become available! 